\title{
Modelling Future Sea-level Change under Green- house Warming Scenarios with an Earth System Model of Intermediate Complexity
}

\author{
O. Makarynskyy, M. Kuhn, W.E. Featherstone \\ Western Australian Centre for Geodesy, Curtin University of Technology, GPO Box U1987, Perth, WA 6845, \\ Australia; Fax: +61 89266 2734; E-mail: makaryno@engmail.cage.curtin.edu.au
}

\begin{abstract}
Recently, a lot of effort has been put into estimating possible near-future changes (say, 10100 years) in the Earth's abiotic system, especially changes induced by human activities. One of the most studied issues is the effect of greenhouse gases on global warming and the corresponding change in sea-level around the world due to the associated deglaciation. On a longer time-scale ( $>100$ years), however, such climatic changes will affect the gravity field, location of the geocentre, and the Earth's rotation vector. In this study, the University of Victoria's (Canada) coupled Earth System Climate Model of intermediate complexity was implemented. The model was used to predict changes in global precipitation, ocean mass redistribution, and seawater salinity and temperature on timescales from hundreds to thousands years under two different greenhouse-warming scenarios. In future, the projected changes will be assimilated into an existing Synthetic Earth Gravity Model to determine the corresponding changes to the location of the geocentre, the Earth's rotation vector, and the geoid.
\end{abstract}

Keywords: Earth system model, greenhouse gas scenario, global warming, sea-level change

\section{Introduction}

Multiple studies of greenhouse-gas effects on the Earth system, considered as an integral system of abiotic and biotic components, have recently been undertaken (e.g., Brovkin et al. 1997; Gallee et al. 1992; Joos et al. 1999; Prinn et al. 1999; among many others). It is due to the widely acknowledged assertion that the Earth's atmospheric temperature is increasing (eg. Houghton et al. 2001), thus causing a number of after-effects, including melting of the previously ice-covered areas (i.e., deglaciation). The latter, together with an increased ocean water temperature, is alleged to cause the phenomenon commonly termed "sea-level rise".

However, sea-level will not necessarily rise in all parts of the globe, and may even fall in some. This was demonstrated in historical changes in sea-level dating back to the last Ice Age (e.g.. Kaufmann 2002; Donato et al. 2000; Feng and Hager 1999), including studies around Australia (e.g., Chappell 1983; Lambeck and Nakada 1990; Milne and Mitrovica 1998). Apart from thermal expansion of the oceans (eustatic rise), there also is a redistribution of mass due to: movement of generally cold and denser fresh water from ice-covered regions to the oceans; changes in the ocean circulation due to the changes in the temperature pattern in the oceans; and isostatic rebound/depression due to surface un/loading. Together, these cause the Earth's centre of gravity (geocentre) and orientation of the spin axis to change (e.g., Gasperani et al. 1986; James and Irvins 1997; Mitrovica et al. 2001).

Importantly, the above redistribution of mass alters the Earth's gravitational field and hence the geoid (e.g., Tamisiea et al. 2001). Since mean sealevel mirrors the geoid (i.e., the flow of water is driven by gravity), the result is that sea-level, though increasing in volume due to the higher temperature, will rise and fall by different amounts in different regions, due to the associated changes in the geocentre, spin axis and geoid. The present study deals with future projections of the geoid by way of climate change based on two different greenhouse-warming scenarios: $2.5 \%$ and $1 \%$ increase of the initial concentration of Carbon Dioxide $\left(\mathrm{CO}_{2}\right)$ per annum. A brief description of the global ocean circulation model (GOCM) used in this study (Section 2) might provide some useful information for an interested reader. Section 3 presents the scenarios considered. The results obtained and following discussion are given in Section 4. Section 5 contains some concluding remarks.

\section{The Model Employed}

The Earth-system model used in this study was the Earth System Climate Model from the University of Victoria, Canada, (UVic ESCM), which is of intermediate complexity (Weaver et al. 2001) and cou- 
ples the atmosphere-ocean-ice processes. The models of intermediate complexity fill the gap between inductive (conceptual) and quasi-deductive (comprehensive) global climate models (Claussen 2002), thus allowing less detailed - though still highly realistic - multiple projections over long time intervals. The UVic ESCM numerically represents the primary thermodynamic and hydrological components of the Earth's climate system in a spherical grid with latitudinal resolution of $3.6^{\circ}$ and longitudinal resolution of $1.8^{\circ}$ (i.e., 100 by 100 grid nodes).

In UVic ESCM, the surface balances and feedbacks of heat, freshwater and momentum of motion are represented using Fanning and Weaver's (1996) diffusive energy-moisture balance atmospheric model. The Modular Ocean Model (Pacanowski 1996) simulates general ocean circulation using primitive equations of motion. The thermodynamics and elastic-viscous plastic dynamics of sea-ice are represented by models with different levels of complexity (e.g., Semtner 1976; Bitz et al. 2001; Holland et al. 2001), which allow estimation of the properties of sea-ice and variations in ice-cover distribution by employing some parameterizations and the momentum balance equations.

The UVic ESCM provides a reliable basis for our long-term ( 2,000 years) experiments to simulate present-day and last glacial maximum climates (Weaver et al. 2001) with outcomes for a number of oceanographic and atmospheric parameters. In our case, the parameters of interest include surface air temperature (SAT; measured/modelled at $\sim 1.5 \mathrm{~m}$ above the ground surface), sea-ice and snow volumes averaged globally, as well as global patterns of precipitation, seawater salinity and potential temperature (temperature of a parcel of water at the sea surface after it has been raised adiabatically - in an insulated container so it does not exchange heat with its surroundings - from some depth in the ocean), and surface pressure in a column of water (Weaver et al. 2001; Pacanowski 1996) due to the rigid-lid approximation. These parameters are of primary importance in the estimation of sea-level and water mass changes.

\section{Scenarios Used}

In the first series of experiments, the ESCM was run until annually averaged surface fluxes became close to zero, thus indicating stabilisation of the system's conditions. This typically takes 2000 years of integration. After such a run, the model output was verified versus present-day climatology. It is claimed (Weaver et al. 2001) that the output is in good agreement with present-day observations. The model's equilibrium state then served a starting point for further numerical experiments under different scenarios of $\mathrm{CO}_{2}$ increase.

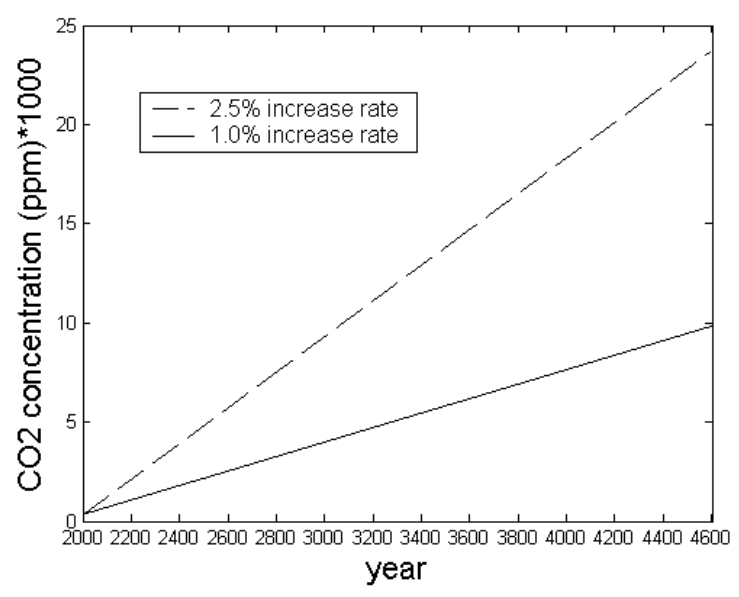

Fig. 1. Change of atmospheric $\mathrm{CO}_{2}$ concentration in the two long-term greenhouse experiments tested.

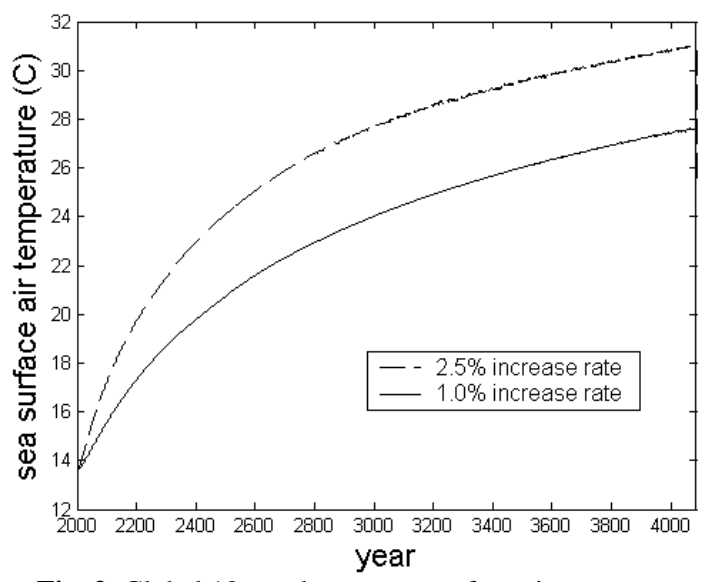

Fig. 2. Global 10-yearly average surface air temperature

In order to estimate the time-scale of sea-ice and snow/glacier melting, the linear option for $\mathrm{CO}_{2}$ increase was used. The rate of the concentration change was 9.00 and $3.65 \mathrm{ppm} /$ year $(2.5 \%$ and $1 \%$ of the initial concentration, respectively) (Fig. 1). The latter linear rate of increase was adopted in the Intergovernmental Panel on Climate Change studies (IPCC 2001), while two and three times higher concentrations were studied by, e.g., Hoyme and Zielke (2001). The linear increase of the greenhouse gas concentration in this study resulted in a non-linear change of the SAT (Fig. 2), which is attributed to the radiative properties of the Earth's atmosphere. 
First, the atmospheric radiance budget is significantly imbalanced with the fast long-wave irradiance accumulation coming from the Earth surface. Then later on, the balance tends to be restored with the increase of the irradiance from the atmosphere to the open space.

\section{Results Obtained and Discussion}

The results of both experiments are similar, with the only significant difference present in the time-scales of the projected changes (Fig. 3). It is clear that the experiment with the $1 \% \mathrm{CO}_{2}$ increase rate takes much longer (about 40\%) to reach the same degree of sea-ice and snow melting than the model run with $2.5 \%$ increase. Therefore, as an equivalent illustrative example, the projection under the $2.5 \%$ rate of $\mathrm{CO}_{2}$ increase will be presented and discussed here.

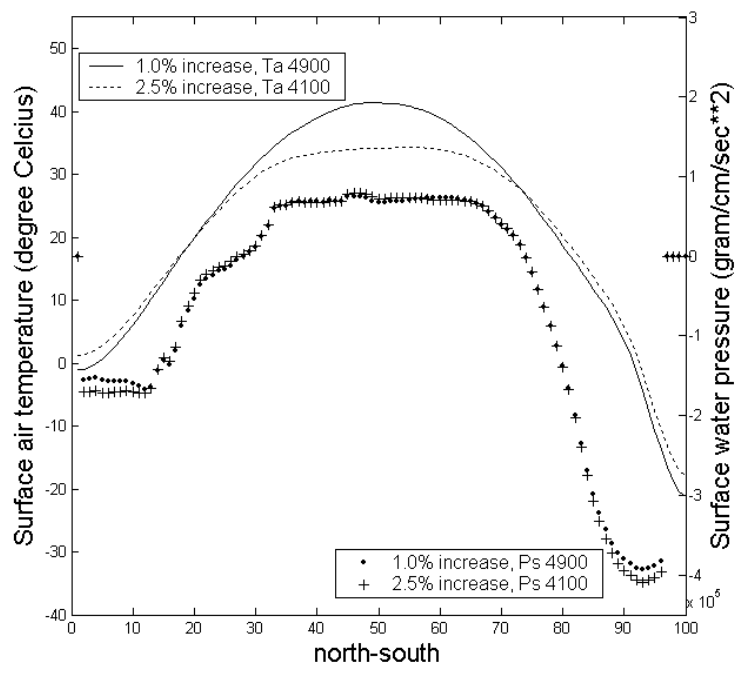

Fig. 3. Zonally averaged profiles of surface air temperature (Ta) and surface water pressure (Ps) in the two long-term greenhouse experiments

This experiment was carried out for a period of 2100 years, from year 2000 to year 4100 . By 4100 , more than half of the initial snow volume has permanently melted (Fig. 4). After that, the value fluctuates around this level insignificantly. In the ESCM model, snow forms when precipitation falls in the areas with the SAT is $\leq-5^{\circ} \mathrm{C}$. Such conditions persist over Antarctic regions (Fig. 3) where snow still accumulates. Meanwhile, the sea-ice has melted almost completely (Fig. 4), with some insignificant masses persisting to form in polar regions during the winter periods.
With the general increase in atmospheric temperature, precipitation increases, leading to overall positive differences (Fig. 5). Following the pattern of precipitation (Fig. 5) and due to the melting of sea-ice in polar regions, both providing fresh-water influx into the oceans, the differences in water salinity between the years 4100 and 2000 are generally negative (i.e., lower salinity) with the lowest values in polar regions (Fig. 6). The processes of snow and sea-ice melting also define the redistribution of water temperature in the oceans (Fig. 7), with absolute minima around the Antarctic exhibiting a lower rate of surface water temperature growth compared to subtropical and equatorial regions. All these factors lead to negative differences in the values of surface water pressure (Fig. 8), thus meaning a decrease of sea-level in these areas. Meanwhile, the spatial distribution of positive differences in water salinity and temperature between years 4100 and 2000 generally coincide with the distribution of higher values of water pressure near southern Africa in the Indian Ocean and between Australia and South America in the Pacific.

A rough estimate of the sea-level change can be derived from the water pressure change as $\Delta H=$ $\Delta P / \mathrm{cm}^{2} \rho_{\mathrm{w}} \mathrm{g}$ (where $\Delta$ is the difference of corresponding parameters, $\rho_{\mathrm{w}}$ is the mean sea water density, $g$ is the gravitational acceleration), which demonstrates the same tendencies (Fig. 9). It is clear that the melt-water from the polar ice shields does not distribute uniformly over the oceans. For instance, Australia undergoes an increase in sea-level to its north and a decrease to its south under this scenario.

Such sea-level redistribution will clearly affect the system Earth (e.g., the gravity field, location of the geocentre, and the Earth's spin axis). The assessment of these effects can only be carried out after the separation of the steric effect from mass changes influencing the general sea-level change. In our further research, the available vertical profiles of water salinity, potential temperature and pressure will be used to perform this separation. Meanwhile, more detailed analysis and coarse quantification of possible sea-level changes form the scope of the present contribution. 


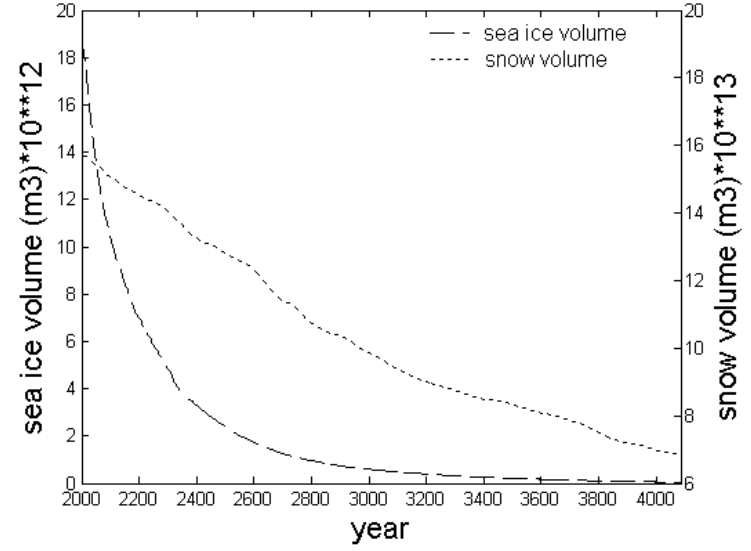

Fig. 4. Globally 10-yearly average sea-ice volume and snow volume change under the scenario of a $2.5 \% / \mathrm{yr} \mathrm{CO}_{2}$ increase

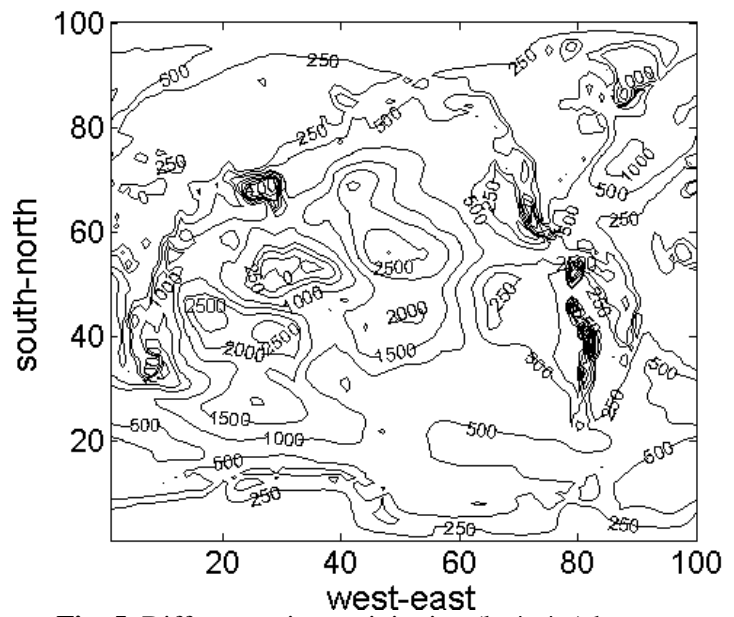

Fig. 5. Differences in precipitation $(\mathrm{kg} / \mathrm{m} / \mathrm{yr})$ between years 4100 and 2000 under the scenario of a $2.5 \% / \mathrm{yr} \mathrm{CO}_{2}$ increase

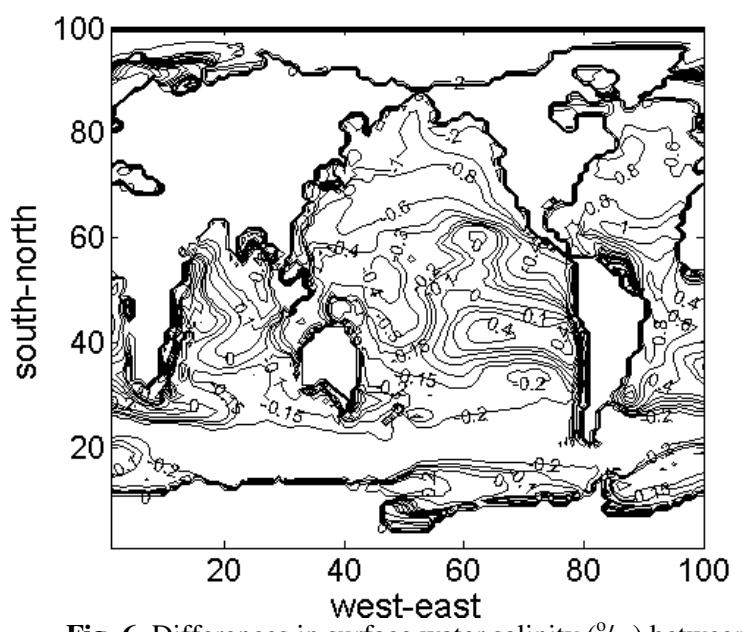

Fig. 6. Differences in surface water salinity $(\%$ oo between years 4100 and 2000 under the scenario of a $2.5 \% / y r \mathrm{CO}_{2}$ increase

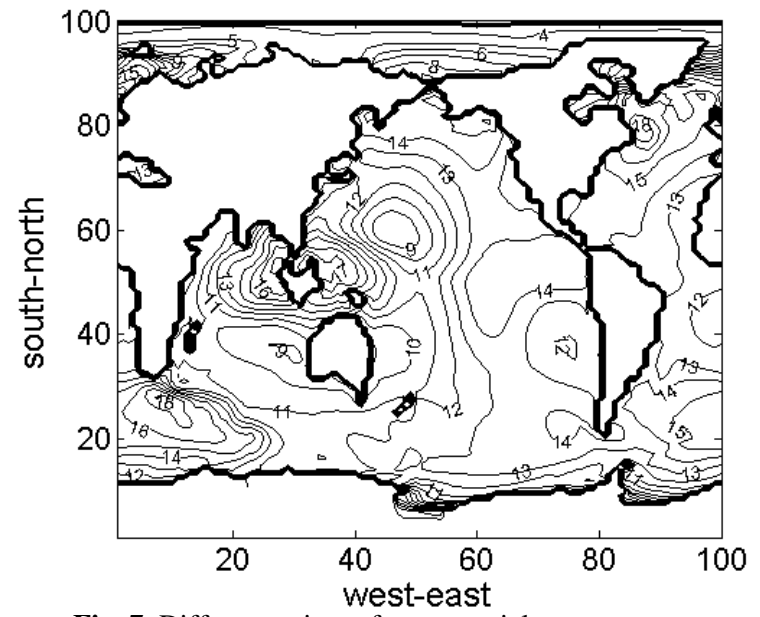

Fig. 7. Differences in surface potential water temperature $\left({ }^{\circ} \mathrm{C}\right)$ between years 4100 and 2000 under the scenario of a $2.5 \% / y r \mathrm{CO}_{2}$ increase

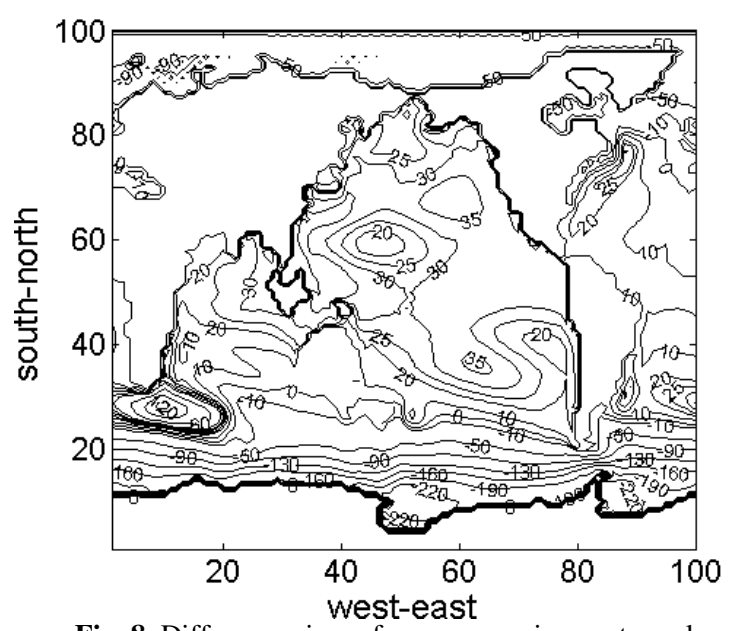

Fig. 8. Differences in surface pressure in a water column $\left(\mathrm{g} / \mathrm{cm} / \mathrm{s}^{2}, * 1000\right)$ between years 4100 and 2000 under the scenario of a $2.5 \% / \mathrm{yr} \mathrm{CO}_{2}$ increase

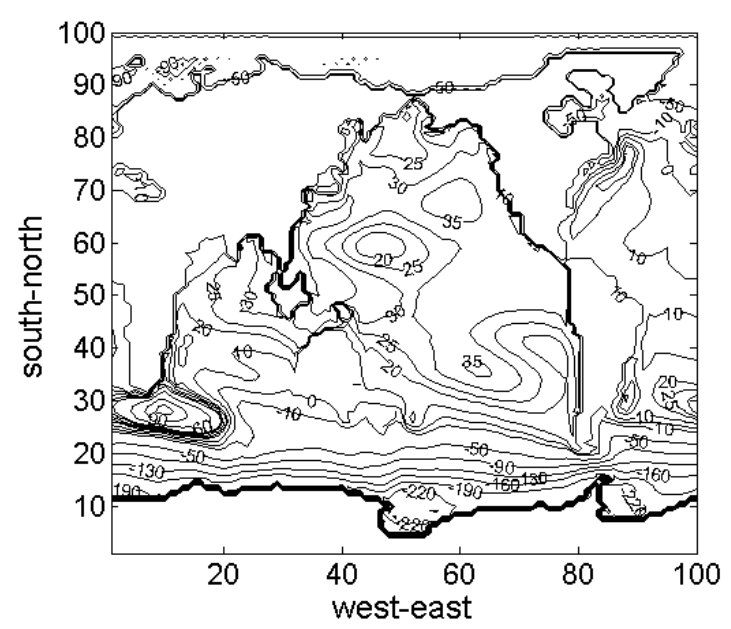

Fig. 9. Differences in sea-level $(\mathrm{cm})$ between years 4100 and 2000 under the scenario of a $2.5 \% / y r \mathrm{CO}_{2}$ increase 


\section{Summary and Future Work}

In this study, the coupled Earth System Climate Model from University of Victoria, Canada (UVic ESCM) of intermediate complexity was implemented to obtain long-term projections of global climate change and ocean mass redistribution. Two continuous numerical experiments were conducted, but only the greenhouse-warming scenario with a $2.5 \%$ per year rate of $\mathrm{CO}_{2}$ increase was presented here. The results demonstrated that the UVic ESCM reflects the general physical tendencies in the change of oceanic parameters, thus providing a basis for the later application to the Synthetic Gravity Model under refinement at Curtin University of Technology (Kuhn and Featherstone 2004).

The inclusion of a continental ice model coupled with the UVic ESCM, which will take place in the near future, will allow a deeper insight into the future climate changes, and a better-based analysis of such projections. These will allow for a fuller evaluation of the expected changes to the geocentre, the Earth's rotation vector, and thence the geoid.

Acknowledgment. This study was funded by the Australian Research Council Discovery-Project grant DP0345583 "Prediction of Sea-level Change around Australia and its Calibration and Validation by Satellite-Geodetic Measurements".

\section{References}

Bitz CM, Holland MM, Weaver AJ, Eby M (2001) Simulating the ice-thickness distribution in a coupled climate model. J Geophys Res 106: 2441-2464

Brovkin V, Ganopolski A, Svirezhev Y (1997) A continuous climate-vegetation classification for use in climatebiosphere studies. Ecological Modelling 101: 251-261

Chappell J (1983) Evidence for smoothly falling sea-level relative to north Queensland, Australia, during the past 6,000 yr, Nature 302: 406-408

Claussen M, Mysak LA, Weaver AJ, Crucifix M, Fichefet T, Loutre M-F, Weber SL, Alcamo J, Alexeev VA, Berger A, Calov R, Ganopolski A, Goosse H, Lohman G, Lunkeit F, Mokhov II, Petoukhov V, Stone P, Wang Zh (2001) Earth system models of intermediate complexity: closing the gap in the spectrum of climate system models, Climate Dynamics 18: 579-586

Donato GD, Vermeersen LLA, Sabadini R (2000) Sea-level changes, geoid and gravity anomalies due to Pleistocene deglaciation by means of multi-layered analytical Earth models, Tectonophysics 320: 409-418

Fanning AG, Weaver AJ (1996) An atmospheric energymoisture model: Climatology, interpentadal climate change and coupling to an ocean general circulation model. J Geophys Res 101: 15111-15128

Fang M, Hager BH (1999) Postglacial sea-level: energy method, Global and Planetary Change 20: 125-156
Gallee H, Van Ypersele JP, Fichefet T, Tricot C, Berger AL (1992) Simulation of the last glacial cycle by a coupled 2D climate-ice sheet model. Part 2: Response to insolation and CO2. J Geophys Res 97: 15713-15740

Gasperini P, Sabadini R, Yuen DA (1986) Excitation of the Earth's rotational axis by recent glacial discharges. Geophys Res Lett 13: 533-536

Holland MM, Bitz CM, Eby M, Weaver AJ (2001) The role of ice ocean interactions in the variability of the North Atlantic thermo-haline circulation. J Clim 14: 656-675

Houghton JT, Ding Y, Griggs DJ, Noguer M, van der Linden PJ, Dai X, Maskell K, Johnson CA (eds) (2001) Climate change 2001: the scientific basis. Contribution of working group 1 to the third assessment report of the intergovernmental panel on climate change. Cambridge Univ Press, Cambridge

Hoyme H, Zielke W (2001) Impact of climate changes on wind behaviour and water levels at the German North Sea coast. Estuarine, Coastal \& Shelf Sci 53(4): 451-458

James TS, Ervins ER (1997) Global geodetic signatures of the Antarctic Ice Sheet. J Geophys Res 102: 605-633

Joos F, Plattner G-K, Stocker TF, Marchal O, Schmittner A (1999) Global warming and marine carbon cycle feedbacks on future atmospheric CO2. Science 284: 464-467

Kaufmann G (2002) Predictions of secular geoid changes from Late Pleistocene and Holocene Antarctic ice-ocean mass balance, Geophys J Int 148: 340-347

Kuhn M, Featherstone WE (2004) Construction of a synthetic Earth gravity model by forward gravity modelling, in: Sideris, M.G. (ed) Proceedings of Sapporo, Springer, Berlin (in press)

Lambeck K, Nakada M (1990) Late Pleistocene and Holocene sea-level change along the Australian coast. Palaeogeog Palaeoclimat Palaeoecol 89: 143-176

Milne GA, Mitrovica JX (1998) The influence of a timedependent ocean-continent geometry on predictions of post-glacial sea-level change in Australia and New Zealand, Geophys Res Lett 25: 793-796

Mitrovica JX, Davies JL, Shapiro II (2001) Recent mass balance of the polar ice sheets inferred from patterns of global sea-level change, Nature 409: 1026-1029

Pacanowski RC (1996) MOM 2 Version 2 Documentation User's Guide and Reference Manual. GFDL Ocean Technical Report 3.2. Princeton

Prinn R, Jacoby H, Sokolov A, Wang C, Xiao X, Yang Z, Eckaus R, Stone P, Ellerman D, Melillo J, Fitzmaurice J, Kicklighter D, Holian G, Liu Y (1999) Integrated global system model for climate policy assessment: feedbacks and sensitivity studies, Climatic Change 41: 469-546

Semtner AJ (1976) A model for the thermodynamic growth of sea ice in numerical investigations of climate, J Physical Oceanography 6: 379-389

Tamisiea ME, Mitrovica JX, Milne GA, Davis JL (2001) Global geoid and sea-level changes due to present-day ice mass fluctuations. J Geophys Res 106: 30849-30865

Weaver AJ, Eby M, Wiebe EC, Bitz CM, Duffy PB, Ewen TL, Fanning AF, Holland MM, MacFadyen A, Damon Matthews H, Meissner KJ, Saenko O, Schmittner A, Wang H, Yoshimori M (2001) The UVic Earth System Climate Model: model description, climatology, and applications to past, present and future climates. Atmosphere-Ocean 39(4): 361-428 